\title{
María Laura Ortiz, Con los vientos del Cordobazo. Los trabajadores clasistas en tiempos de violencia y represión, Editorial de la Universidad Nacional de Córdoba, Córdoba, 2019
}

Marina Giraudo*

A cincuenta años del Cordobazo, María Laura Ortiz nos invita a reflexionar sobre el mundo obrero cordobés con esta exhaustiva investigación. Enmarcada en un análisis históricamente situado que vincula coyunturas con estructuras y acciones sociales con condiciones de posibilidad, la autora realiza una relectura de la emergencia y la trayectoria del clasismo cordobés entre 1969 y 1982. A partir del reconocimiento de otras propuestas interpretativas, este estudio profundiza en los vínculos entre la cultura obrera local y las prácticas sindicales clasistas poniendo en cuestión diversas perspectivas nacionales generalizadoras. La estructura del trabajo reposa en una (re)conceptualización del clasismo que supera definiciones estáticas y dicotómicas en torno a la identidad clasista y las tradiciones políticas con las que se identifican.

A los efectos de ampliar las pesquisas y superar ciertos esquemas y barreras historiográficas, Ortiz recupera memorias del pasado reciente y objetiva los sentidos que subyacen en las tradiciones obreras, indagando en fuentes inéditas - como los "archivos de la represión" - mediante el uso de una pertinente metodología científica propuesta por la historia oral y cultural que dota de originalidad al texto. Dos partes

\footnotetext{
* Universidad Nacional de Córdoba. CONICET. E mail: marinagiraudorinaudo@gmail.com
} 
organizan la investigación, siendo la primera la que por un lado refuerza aquella conceptualización a partir de los aportes culturalistas de algunos autores como Raymond Williams, Eric Hobsbawm, Richard Hoggart y James Petras. Por otro lado, y al mismo tiempo, la noción de clasismo es reinterpretada a partir de la caracterización del modelo industrial cordobés, la lógica de funcionamiento entre lo industrial y lo territorial en la ciudad y las transformaciones económicas, sociales y culturales ocurridas con el Cordobazo, el Navarrazo y el golpe de Estado de 1976; acontecimientos que incidieron sobre las posibilidades de expresión de las organizaciones clasistas.

Como resalta la historiografía hegemónica sobre el tema - y retoma detenidamente Ortiz en este libro - la experiencia clasista cordobesa precursora fue la de los sindicatos de Fiat Concord (Sitrac), Fiat Materfer (Sitram) y el Sindicato de Mecánicos y Afines del Transporte Automotor (Smata). Sin embargo, la autora añade en su análisis una serie de experiencias clasistas que, si bien no llegaron a dirigir sus respectivos sindicatos, se presentaron en distintos sectores productivos: fábricas mecánicas y metalúrgicas, de vidrio, de calzado, de caucho, en establecimientos lácteos y de la carne, obras de construcción y el sector de la sanidad; esto le permite no sólo ampliar la casuística sino contribuir a la reproblematización del pasado reciente en clave local.

Con los vientos del Cordobazo, emerge tempranamente el clasismo cordobés atravesado, entre otras cosas, por la cultura política revolucionaria forjada en el marco de la dictadura militar. La resignificación de tradiciones colectivas de clase pasadas en nuevas experiencias, le permite a la autora repensar la noción de clasismo como una serie de valores, ideas, prácticas, mitos y memorias de la cultura obrera cordobesa. Estas experiencias, heredadas o compartidas, se vincularon con la militancia revolucionaria de izquierda - protagonista a fines de los años sesenta y principio de los setenta - y emergieron bajo ciertos contenidos antiburocráticos y revolucionarios, de una ética alternativa a la tradición sindical peronista basada en la negociación. Este espacio identitario que se diferencia de otras experiencias sindicales, es presentado como un fenómeno histórico activo, una expresión política y cultural de un conjunto de trabajadores y trabajadoras, que se debieron tanto a la acción de los sujetos como al condicionamiento estructural. 
Es precisamente esta caracterización la que se desprende de un exhaustivo análisis de fuentes que muestra, entre otras cosas, que esa identidad clasista - producto de una experiencia colectiva transmitida generacionalmente también en obreros sin experticia - no se puede identificar directamente con una tradición partidaria o ideológica. Si bien, "esas tradiciones transmitían ciertos valores que fueron compatibles con el discurso de izquierda a principios de los años 70, y fue lo que dio sustento al clasismo" " cordobés, esta identidad obrera fue "una (re)invención que se desarrolló en una praxis propia de la clase y producto de la acumulación de un pasado seleccionado a partir de un presente de emergencia en la cultura política"2 local. De esta manera, la autora identifica una diversidad de tradiciones que atravesaron al clasismo como una estrategia sindical polisémica que fue transformando sus modalidades de acción de acuerdo a las cambiantes coyunturas. Establece así un diálogo crítico con autores como James Brennan, Mónica Gordillo y Daniel James, quienes en sus estudios les otorgaron un papel pasivo a los dirigentes clasistas, identificados como pro socialistas en oposición a los trabajadores de base peronistas.

De ese sincretismo que caracterizó al clasismo cordobés se desprende una diversidad de formas de organización que le fueron propias y que pervivieron durante la resistencia en el marco del terrorismo de Estado: la emergencia de redes horizontales de solidaridad entre activistas y sindicatos, la autoorganización obrera y el empleo de la violencia en sus repertorios de acción y confrontación.

En la segunda parte del libro Ortiz expone la trayectoria, los repertorios de acción y las formas de organización de las agrupaciones clasistas en diferentes gremios y empresas, a partir de las reconfiguraciones del bloque social dominante y las transformaciones económicas que influyeron en la capacidad transformadora de la clase obrera en el marco de una periodización que inicia con el Cordobazo y culmina con el final del terrorismo de Estado. En la primera etapa, la autora distingue que no fue la posición en el mercado productivo lo que hizo posible la emergencia de un movimiento de base clasista y/o combativo: todos los casos emergen de una situación de descontento obrero que no pudo ser canalizada a través de la estructura sindical existente, por lo que buscó caminos por fuera y al margen de ella. Asimismo, la

1 Ortiz, 2019: 174.

2 Ortiz, 2019: 197. 
violencia fue parte de la cultura de la clase y era un recurso compartido por todas las experiencias sindicales. Entre 1972 y 1974 el clasismo fue atravesado por la estrategia electoral, por lo que tendió a radicalizarse el activismo sindical al mismo tiempo que se mantenía como una cultura contrarrevolucionaria residual.

A partir del triunfo del Navarrazo y de la ejecución del plenario normalizador de la Confederación General del Trabajo regional Córdoba en 1974 se abrió una nueva etapa para el clasismo cordobés, caracterizada por la reemergencia de una cultura política reaccionaria, bajo una organización defensiva de sus acciones, expresadas de formas más precarias ya sea en cuerpos de delegados, comisiones internas o agrupaciones denominadas "en la resistencia". La represión sindical y estatal fue disolviendo los canales de expresión pública y masiva y apuntalaba a las redes horizontales que durante años había construido el sindicalismo clasista. A partir del golpe de Estado de 1976 la modalidad de acción obrera defensiva continuó en oposición a la dictadura, intercalando manifestaciones visibles y modalidades que evitaron la identificación de responsabilidades, perviviendo ciertas formas de organización clasista.

Este trabajo investigativo constituye una propuesta interesante en tanto supera esquemas y barreras historiográficas en clave nacional, a partir de un abordaje que pone el foco en identificar las especificidades y diversidades que se desprenden en el ámbito regional. En este sentido, la autora identifica el comienzo del terrorismo de Estado a partir del Navarrazo, acontecimiento que puso en evidencia el accionar clandestino del Estado - los primeros detenidos y desaparecidos en la provincia datan de 1975 - bajo la connivencia de la Policía provincial y el Ministerio de Bienestar Social, apoyados por el Poder Judicial y los comandos peronistas ortodoxos. Además de este cuestionamiento en torno a la periodización para el período dictatorial en clave regional, la evidencia analizada por Ortiz le permite diferenciarse de ciertas posturas teóricas pregonadas por James, Basualdo y Lorenz que aseguran que la represión institucional se ejerció fácilmente en los militantes sindicales de base ya que no contaban con una estructura partidaria que los contuviera para ingresar en la clandestinidad. La experiencia local demuestra que en Córdoba los dirigentes clasistas más reconocidos habían tenido que abandonar sus puestos de trabajo a partir de 1974, y esconderse, debilitando las redes de organización obrera, ya que eran perseguidos o tenían pedido de captura formal. Tal como aclara la autora, esta situación benefició al 
empresariado cordobés en el avance de las reformas laborales y económicas necesarias para la acumulación de riqueza. En este sentido, sostiene asimismo que para el caso cordobés no se produjo un pasaje de una resistencia fragmentaria a una de mayor organización sindical a partir de 1979 como interpreta Pozzi en un análisis que prioriza la escala nacional a partir de casos de Capital Federal y Gran Buenos Aires. En Córdoba el accionar de la clase obrera fue disminuyendo a fines de aquel año, al mismo tiempo que lo hacían las operaciones represivas del Estado, y se inició así la reinstitucionalización sindical a partir de la ley $\mathrm{N}^{\circ} 22.105$ de Asociaciones Profesionales. De esta manera, las fuentes indagadas le permitieron a la autora repensar y reflexionar en torno a estas diferencias locales sobre la oposición obrera a la dictadura, disponiendo que para fines de 1979 se cerraba en la provincia el ciclo de represión iniciado en el año 1974.

Todas estas reflexiones propuestas por María Laura Ortiz tienen su fundamento en una de las potencialidades más importantes que caracterizan a este trabajo: la diversidad de fuentes, ya sean orales, documentos sindicales y políticos, expedientes judiciales, documentos desclasificados, revistas, publicaciones periódicas, sindicales, partidarias y gubernamentales. El uso de herramientas metodológicas provenientes de la historia oral le permitió a la autora someter el testimonio a la crítica y al entrecruzamiento con otras fuentes históricas, haciendo un uso instrumental ${ }^{3}$ del mismo en la preservación de las memorias. Resulta de suma importancia resaltar que en la interpretación que realiza la autora de las memorias sociales sobre los setenta, tiene en cuenta los múltiples acontecimientos que se sucedieron a partir de la transición democrática hasta la actualidad y que pudieron permear y operar sobre las memorias. Es entonces en el cruce de memorias e historia que la autora reinterpreta, problematiza y revaloriza un pasado reciente históricamente situado, recordado, olvidado o silenciado por el sector trabajador argentino.

Finalmente, es importante destacar especialmente el compromiso académico y político presente en el libro de Ortiz. La labor realizada por la autora en la desclasificación de documentos de los servicios de inteligencia de la Policía o el Ejército - representados en Córdoba por los memorándums y radiogramas de la Policía Federal Argentina -

3 Franco \& Levín, 2007. 
otorgó claridad a los Espacios de Memoria y al Archivo en donde se encuentran, en torno a la información que disponen para la reconstrucción de nuevas verdades, de un pasado reciente aún desconocido, que impulsen la continuidad de los procesos de justicia. Asimismo, esta publicación se suma al vasto, reciente y renovado interés por la articulación de niveles micro y macro, la larga y la corta duración, lo local y/o lo regional con lo nacional y transnacional, las dimensiones de lo económico-demográfico con lo simbólico, imaginario e identitario. ${ }^{4}$ Esta renovación epistemológica y metodológica que emerge a partir de los años ochenta, influenciada por diversas tradiciones - entre ellas, el marxismo británico, marco teórico relevante para Ortiz posicionaron a lo regional y lo local como escalas de observación, en tanto pasaron a ser considerados espacios de producción política, social y cultural.

4 Jensen, 2010. 


\section{BIBLIOGRAFÍA}

Franco, M. \& Levín F. 2007, "El pasado cercano en clave historiográfica" en Franco M. \& Levín F. (Comps) Historia reciente. Perspectivas y desafíos para un campo en construcción, Paidós, Buenos Aires.

Jensen, S. 2010, “Diálogos entre la historia local y la historia reciente en Argentina. Bahía Blanca durante la última dictadura militar" en XIV Encuentro de Latinoamericanistas Españoles: congreso internacional, Universidade de Santiago de Compostela, Centro Interdisciplinario de Estudios Americanistas Gumersindo Busto, Consejo Español de Estudios Iberoamericanos, pp. 1426 a 1447.

Ortiz, M. L. 2019, Con los vientos del Cordobazo. Los trabajadores clasistas en tiempos de violencia y represión, Editorial de la Universidad Nacional de Córdoba, Córdoba. 